\title{
Functionalized Nanodiamonds Part 3: Thiolation of Tertiary/Bridgehead Alcohols
}

\author{
Boryslav A. Tkachenko, ${ }^{\text {a }}$ Natalie A. Fokina, ${ }^{\text {a }}$ Lesya V. Chernish, ${ }^{b}$ Jeremy E. P. Dahl, ${ }^{c}$ \\ Shenggao G. Liu, ${ }^{c}$ Robert M. K. Carlson, ${ }^{c}$ Andrey A. Fokin, ${ }^{a, b_{*}}$ and Peter R. Schreiner ${ }^{a *}$
}

(a) Institut für Organische Chemie, Justus-Liebig University, Heinrich-Buff-Ring 58, D-35392 Giessen (Germany), (b) Department of Organic Chemistry, Kiev Polytechnic Institute, pr. Pobedy 37, 03056 Kiev (Ukraine), and (c) MolecularDiamond Technologies, Chevron Technology Ventures, 100 Chevron Way, Richmond, CA 94802 (USA)

\section{Contents}

${ }^{13} \mathrm{C}$ NMR Spectra of thiols $\mathrm{S} 2-14$

\begin{tabular}{|c|c|c|}
\hline 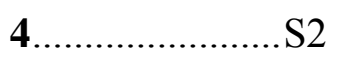 & 9 & ........... S10 \\
\hline 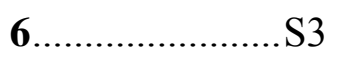 & $10 \ldots \ldots \ldots \ldots \ldots \ldots . . . \mathrm{S} 7$ & ......S 11 \\
\hline 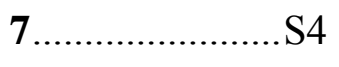 & $11 \ldots \ldots \ldots \ldots \ldots \ldots . . . \mathrm{S} 8$ & $15 \ldots \ldots \ldots \ldots \ldots . . . \mathrm{S} 12$ \\
\hline ...S5 & S9 & 31. \\
\hline
\end{tabular}

${ }^{1} \mathrm{H}$ and ${ }^{13} \mathrm{C}$ NMR spectra were recorded on a Bruker AM 400 spectrometer at $298 \mathrm{~K}$ in $5 \mathrm{~mm}$ NMR tubes, operating at 400.1 and $100.6 \mathrm{MHz}$, respectively. The chemical shifts ( $\delta$ values) were obtained in $\mathrm{CDCl}_{3}$ solutions unless otherwise is noted and referenced to residual $\mathrm{CHCl}_{3}\left(\delta{ }^{1} \mathrm{H} 7.25 \mathrm{ppm}\right)$ and $(\delta$ $\left.{ }^{13} \mathrm{C} 77.2 \mathrm{ppm}\right)$. The ${ }^{13} \mathrm{C}$ NMR spectra were acquired using the broadband proton decoupling mode and the DEPT technique. The assignments of the ${ }^{13} \mathrm{C}$ resonances of all compounds were deduced from the application of heteronuclear correlation technique and the DEPT technique. 


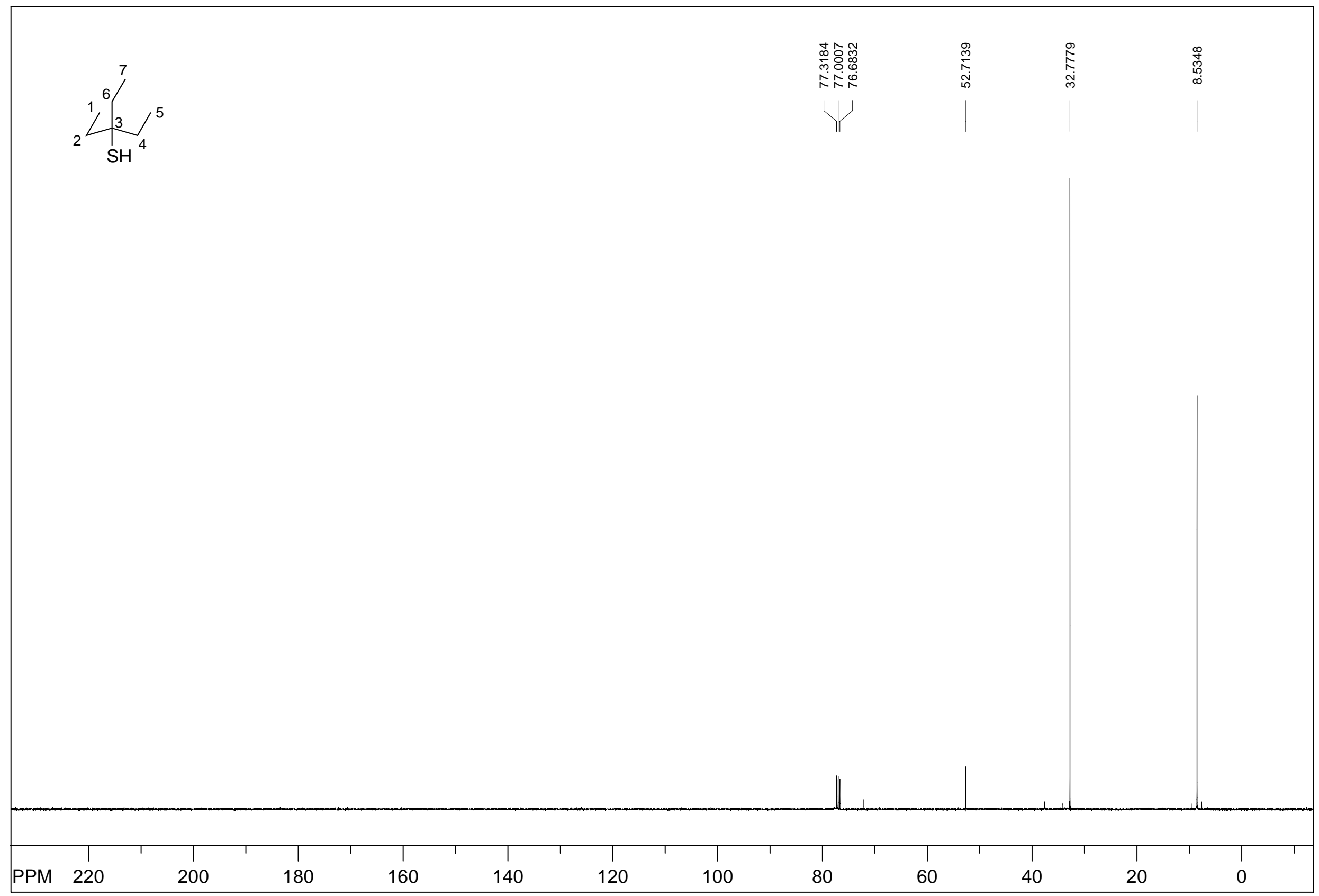

3-Ethylpentane-3-thiol (4) 


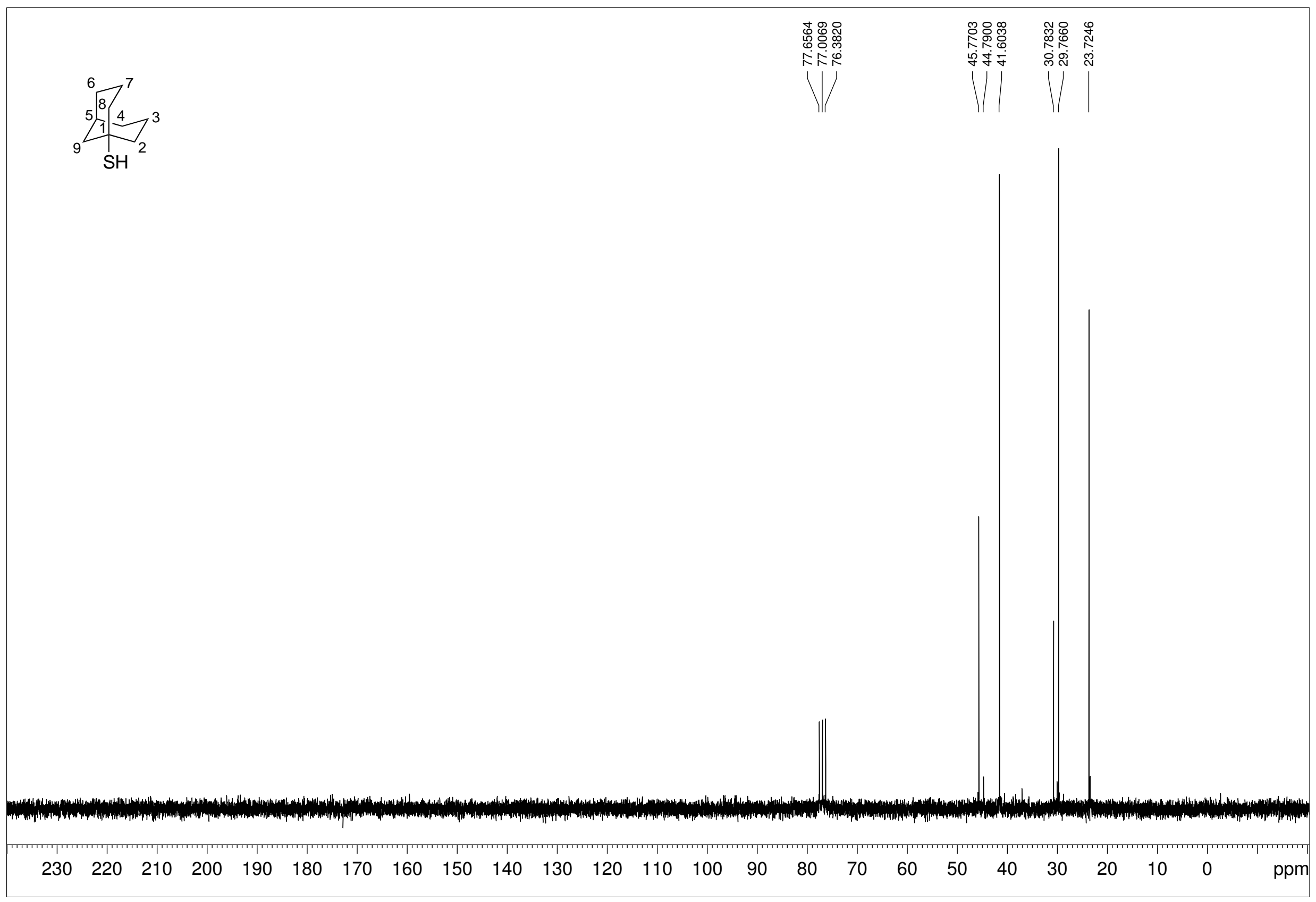

Bicyclo[3.3.1]nonane-1-thiol (6) 


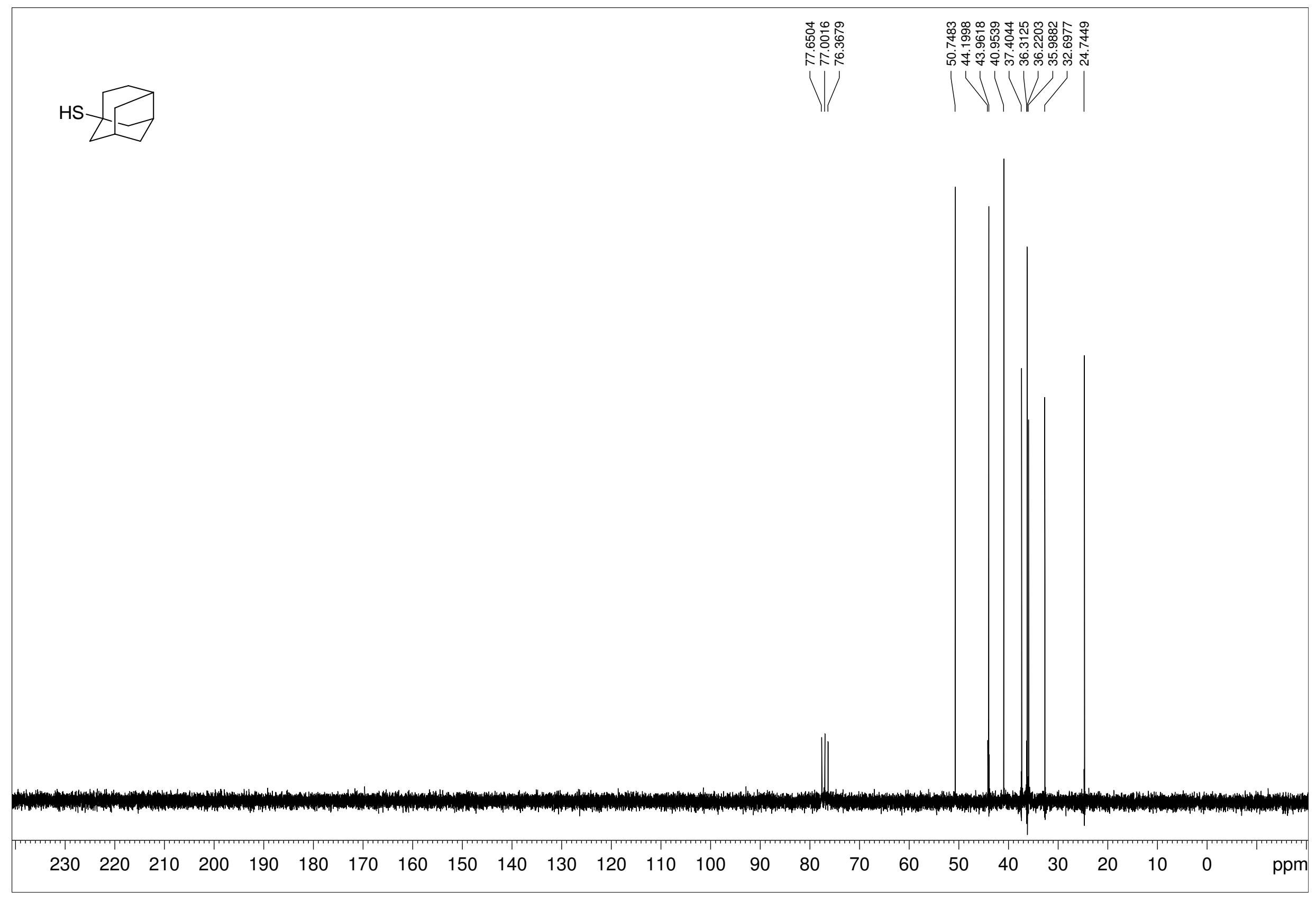

Protoadamantane-6-thiol (7) 


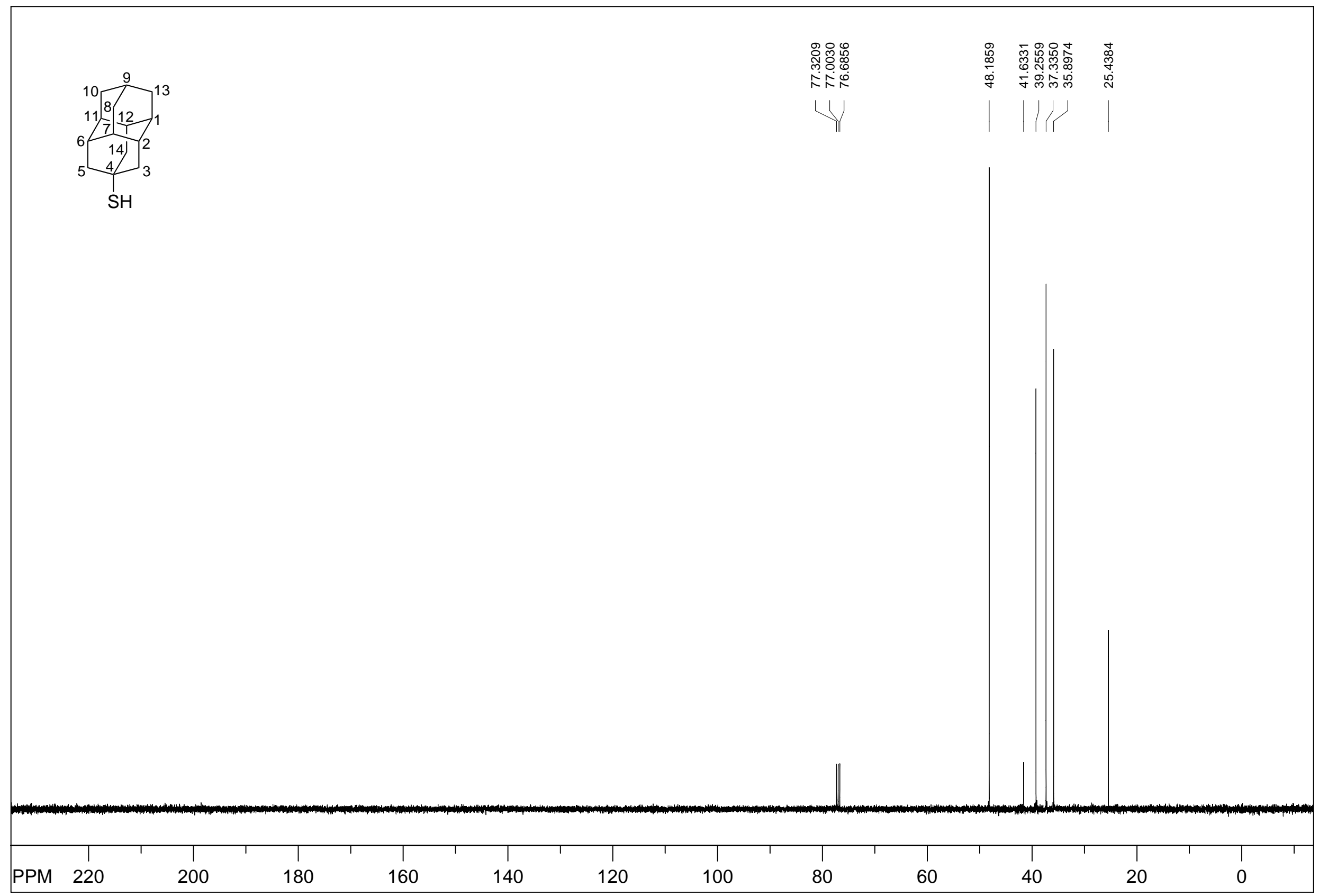

Diamantane-4-thiol (8) 


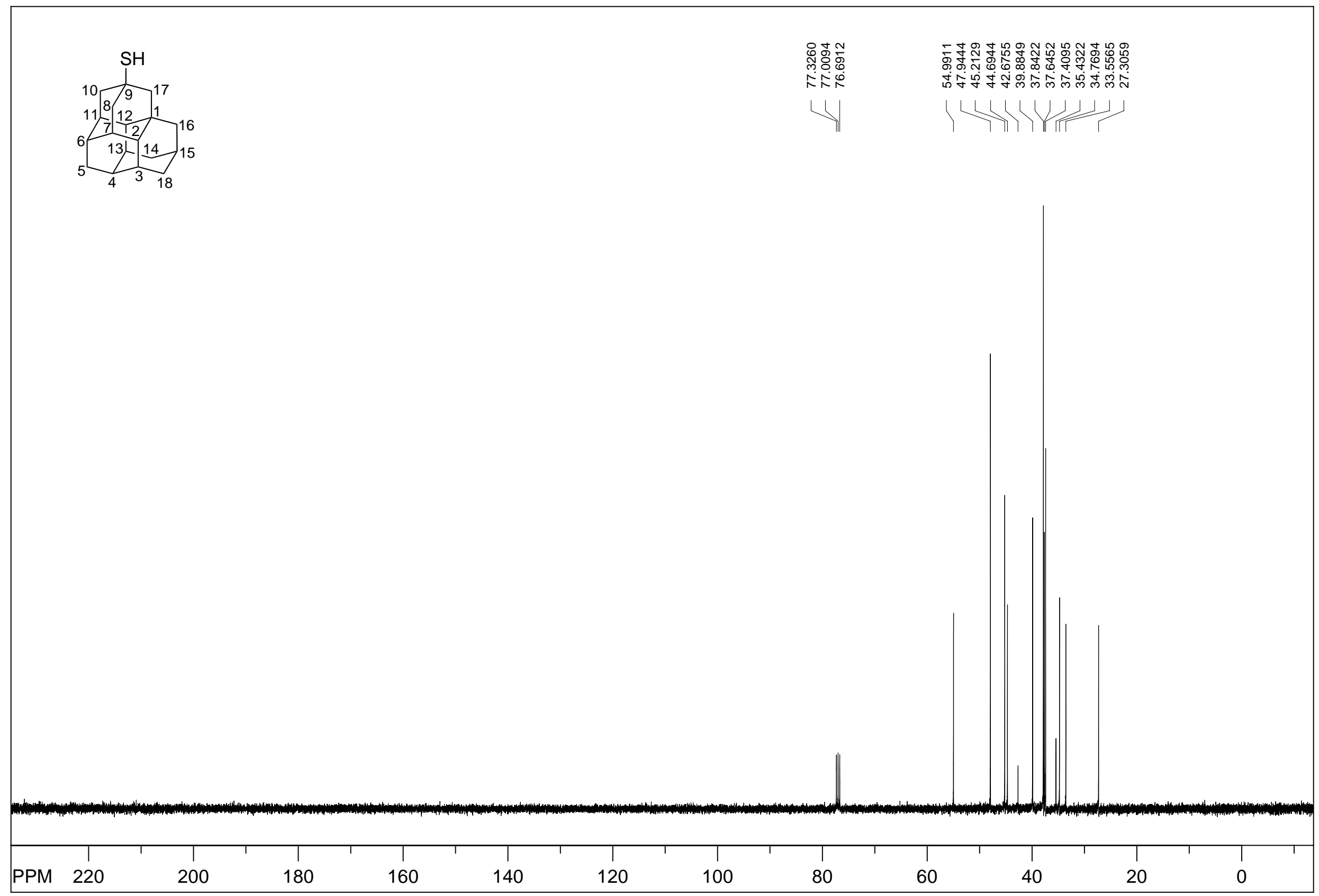

Triamantane-9-thiol (9) 


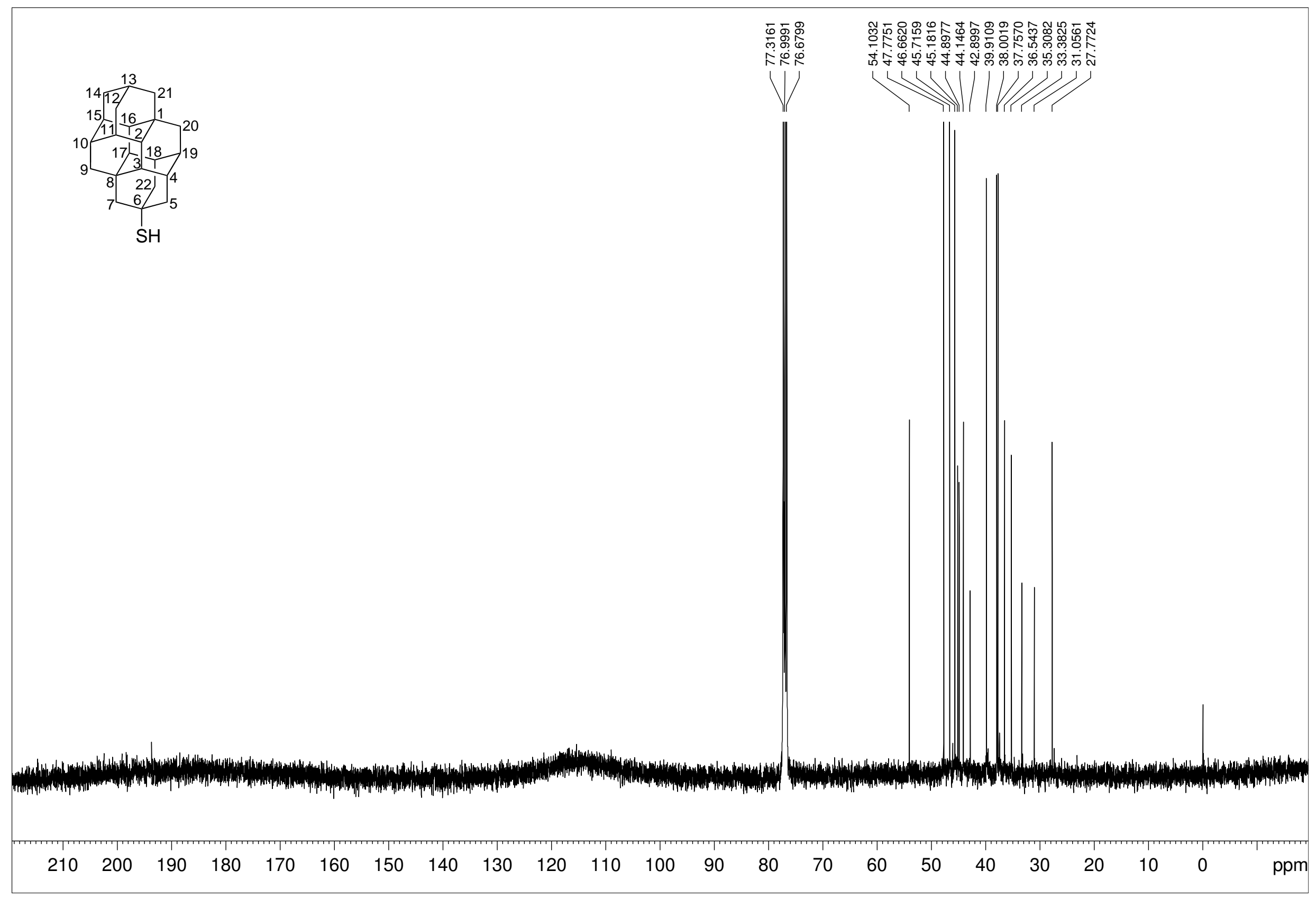

\section{[121]Tetramantane-6-thiol (10)}




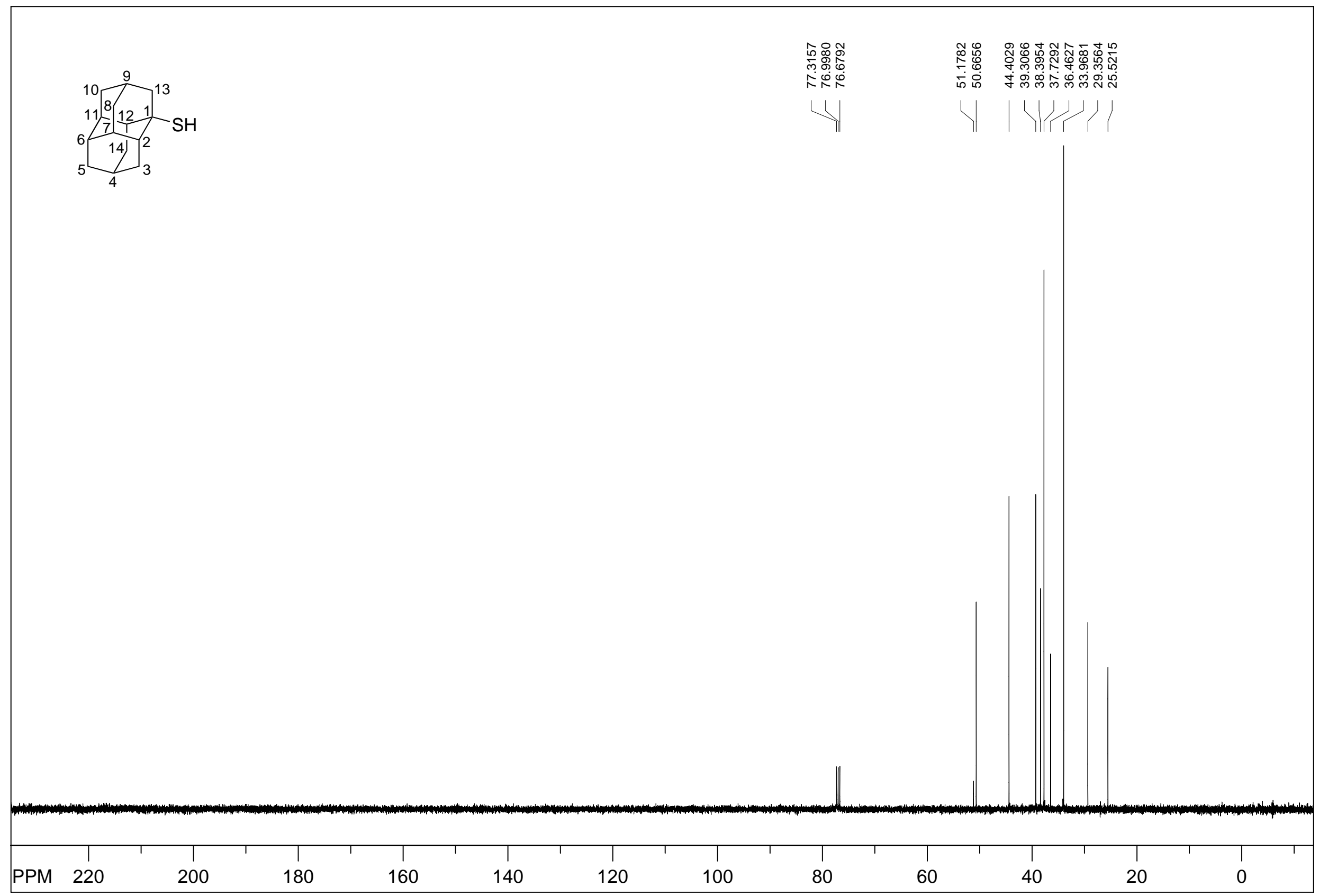

Diamantane-1-thiol (11) 


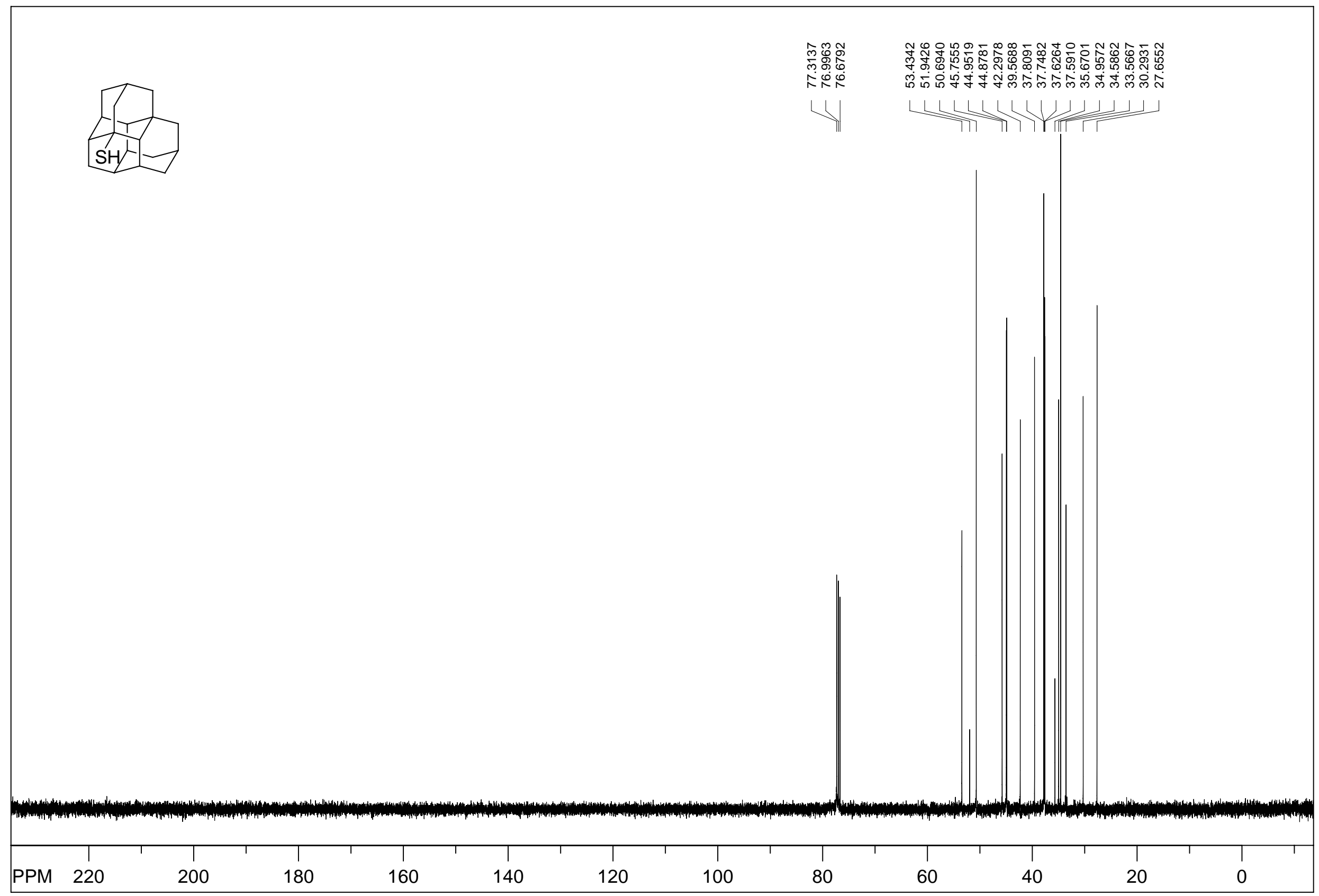

Triamantane-3-thiol (12) 


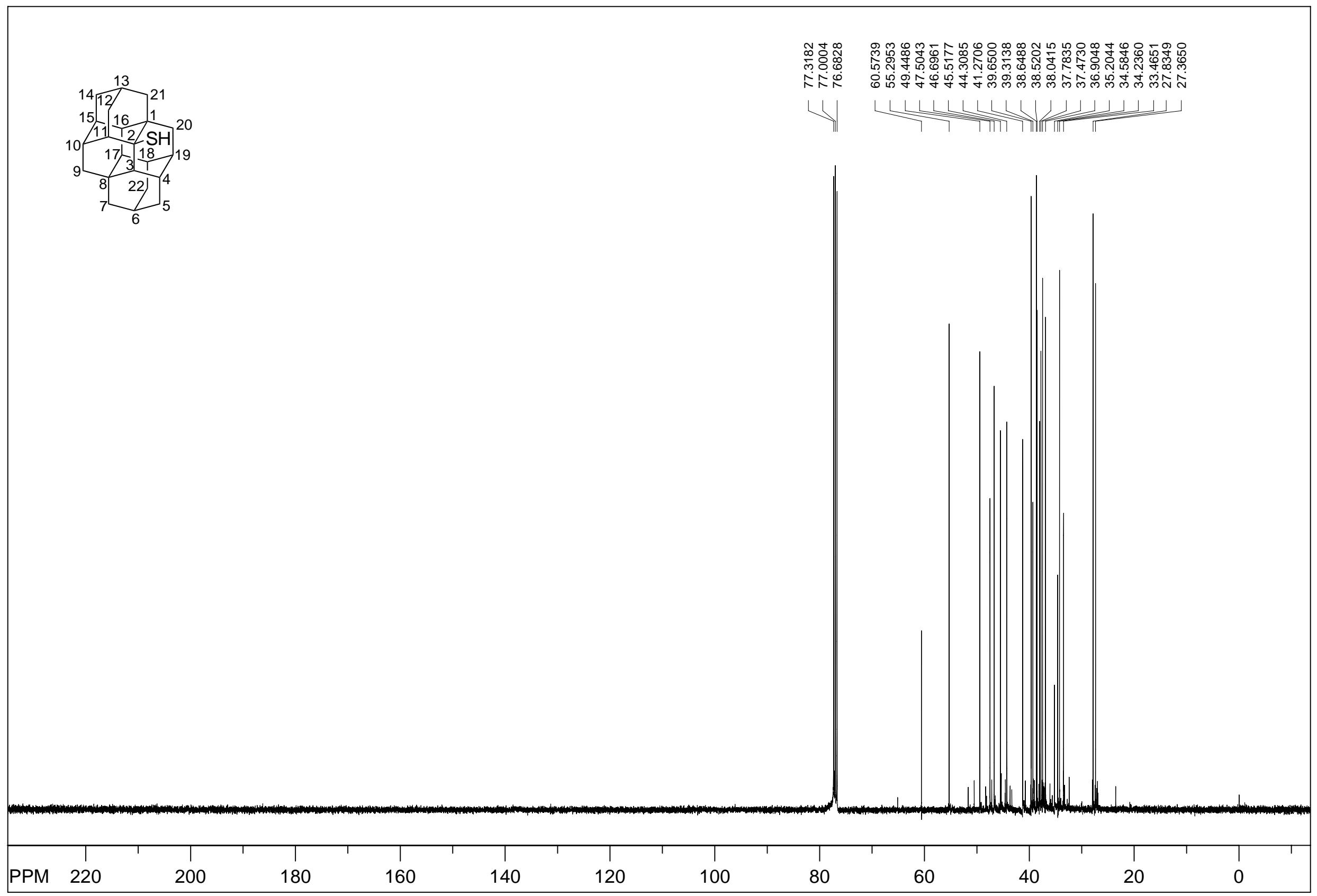

[121]Tetramantane-2-thiol (13) 


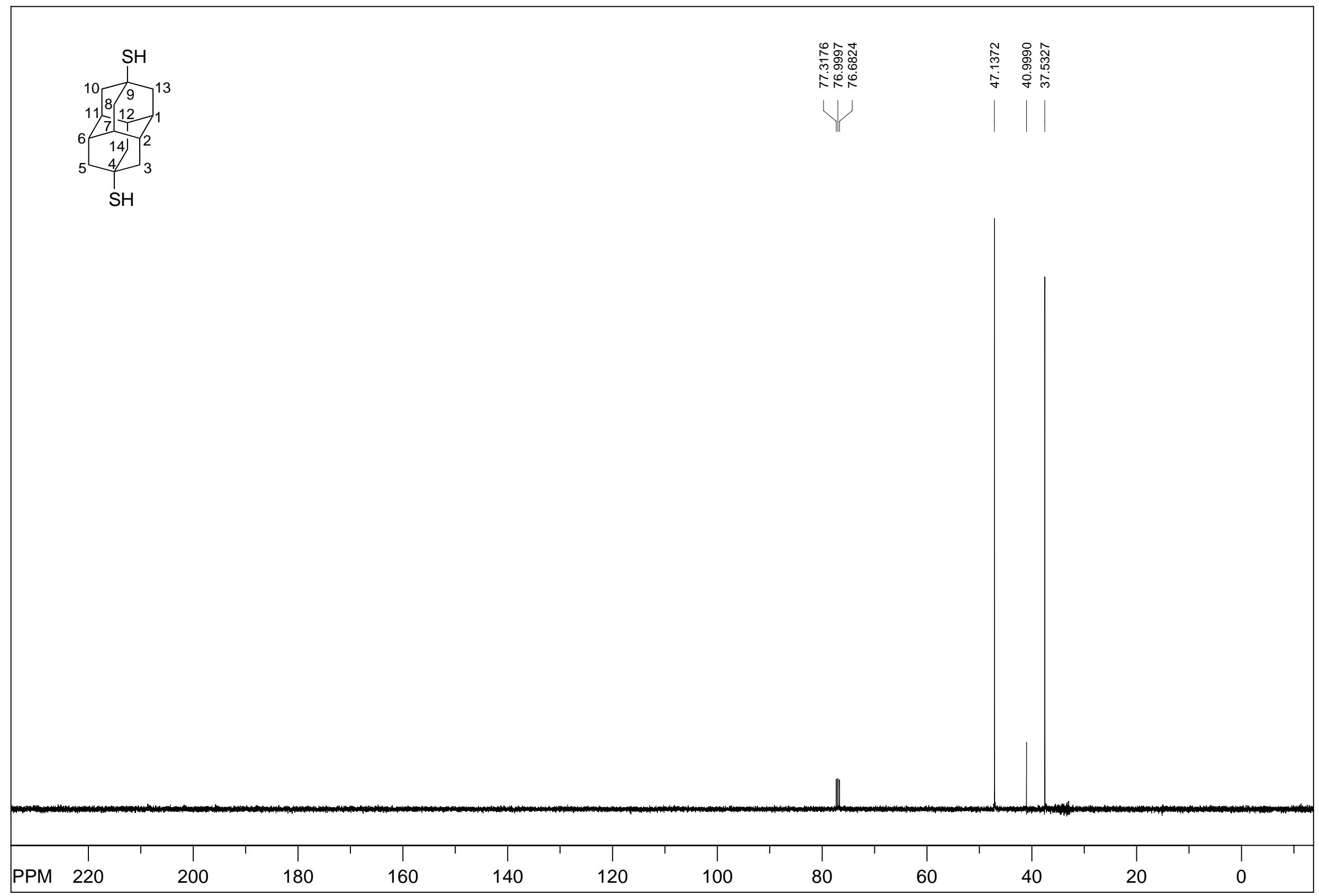

Diamantane-4,9-dithiol (14) 


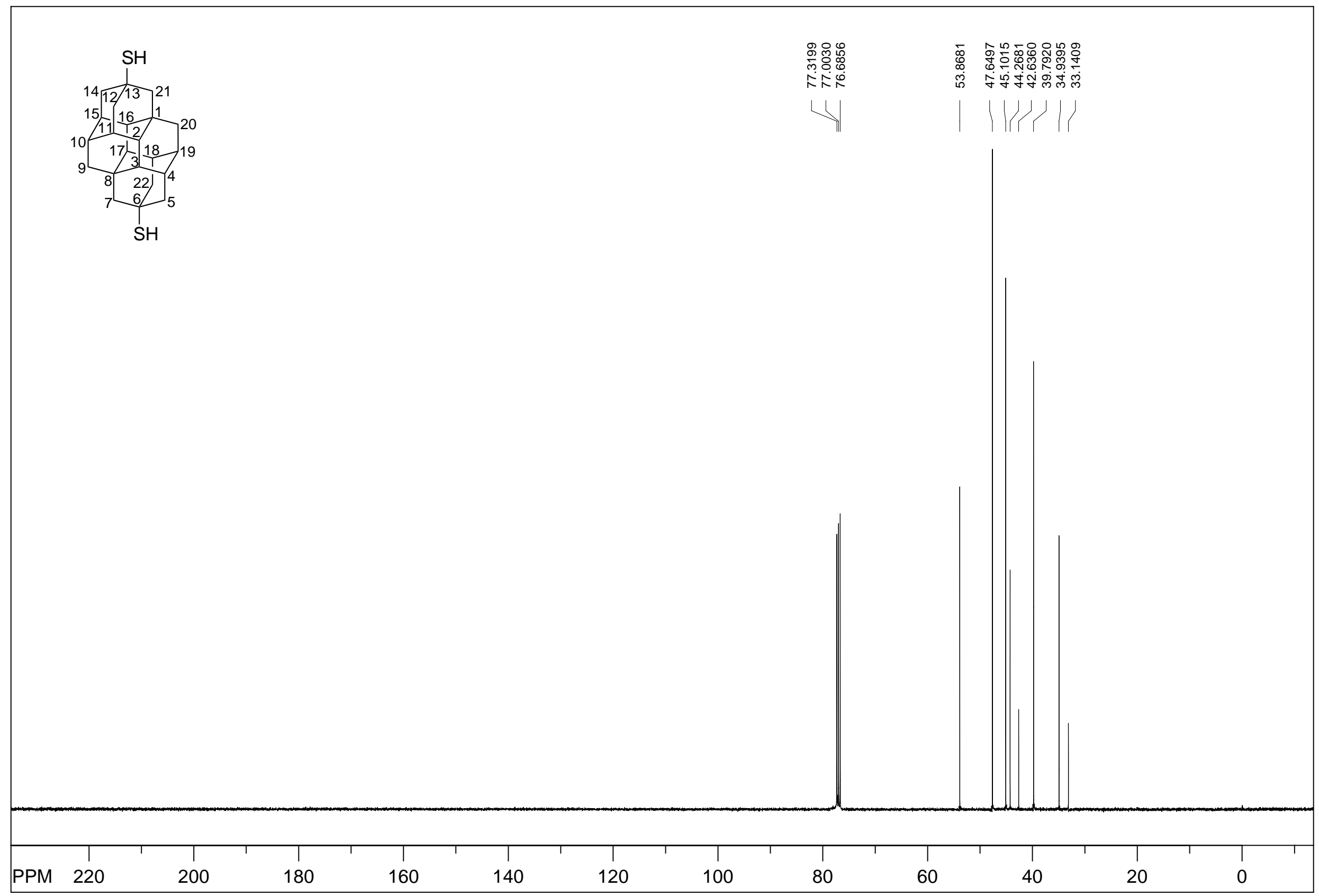

[121]Tetramantane-6,13-dithiol (15) 


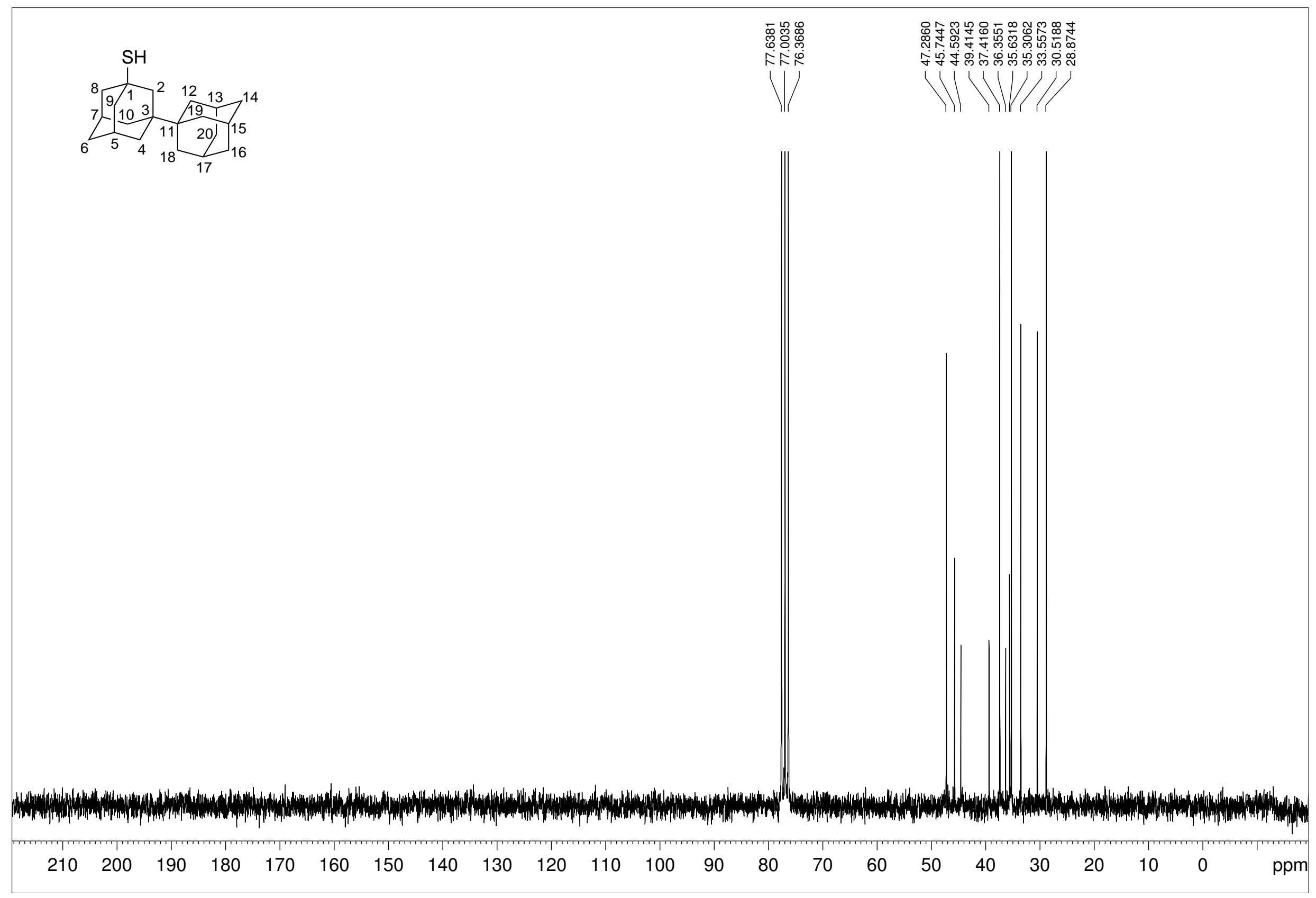

1,1'-diadamantane-3-thiol (31) 


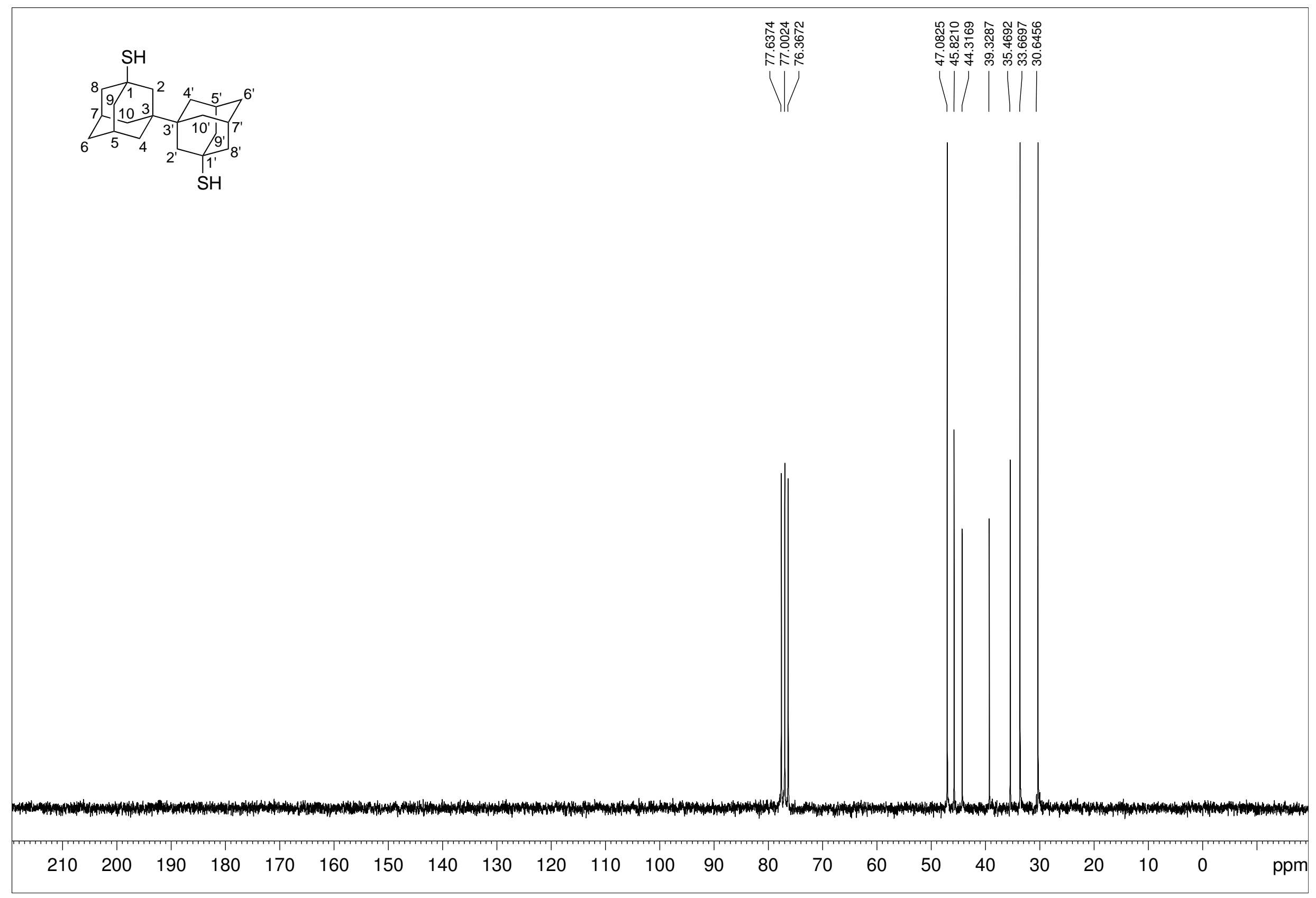

1,1'-diadamantane-3,3'-dithiol (32) 